\title{
Hybrid Renewable Power Generation for Modeling and Controlling the Battery Storage Photovoltaic System
}

\author{
Mohd Mustafa $\left(\mathbb{D},{ }^{1}\right.$ G. Anandhakumar $\mathbb{D}^{2}$, Anju Anna Jacob $(\mathbb{D})^{3}$ \\ Ngangbam Phalguni Singh $\mathbb{D}^{4},{ }^{4}$ S. Asha $\mathbb{D}^{5},{ }^{5}$ and S. Arockia Jayadhas ${ }^{6}{ }^{6}$ \\ ${ }^{1}$ Department of Electrical and Electronics Engineering, Saveetha School of Engineering, Saveetha Institute of Medical and \\ Technical Sciences, Chennai, 602105 Tamil Nadu, India \\ ${ }^{2}$ Department of Energy and Environmental Engineering, Saveetha School of Engineering, Saveetha Institute of Medical and \\ Technical Sciences, Chennai, 602105 Tamil Nadu, India \\ ${ }^{3}$ School of Engineering, Emirates Aviation University, Dubai, UAE \\ ${ }^{4}$ Department of Electronics and Communication Engineering, Koneru Lakshmaiah Education Foundation, KL Deemed to \\ be University, Vaddeswaram, Andhra Pradesh, India \\ ${ }^{5}$ Department of Electronics and Communication Engineering, Saveetha Engineering College, Chennai, 602105 Tamil Nadu, India \\ ${ }^{6}$ Department of EECE St. Joseph University in Tanzania, Tanzania
}

Correspondence should be addressed to Mohd Mustafa; mustafakmcet@gmail.com

and S. Arockia Jayadhas; arockia.jayadhas@sjuit.ac.tz

Received 22 January 2022; Revised 4 February 2022; Accepted 7 February 2022; Published 27 February 2022

Academic Editor: V. Mohanavel

Copyright ( 2022 Mohd Mustafa et al. This is an open access article distributed under the Creative Commons Attribution License, which permits unrestricted use, distribution, and reproduction in any medium, provided the original work is properly cited.

A major portion of the global energy demand was likely to be fulfilled by an extensive supply of renewable power. Renewable energy outputs, on the other hand, are changeable due to the dynamic nature of their sources. The integration of these variable sources of power into current power grids is proving difficult for electrical power system operators all around the world. The fundamental issue with renewable energy systems is that, due to the stochastic nature of renewable power, electricity production varies from period to period. Recent research and development on renewable technologies can ensure the islands' long-term electricity supply. Renewable energy sources, on the other hand, are limited by their unpredictable nature and significant reliance on weather conditions. To offset this disadvantage, several renewable energy sources and converters must be joined. To balance the power generation and load power, a hybrid renewable power generation for standalone application is proposed. The solar plant model is made up of a $170 \mathrm{~W}$ photovoltaic (PV) panel connected in series, and conversion of energy is done using the maximum power point tracking (MPPT) algorithm, which regulates a buck-boost converter modulation. The MPPT method used in the converter's control step is based on perturb and observe (P\&O) and enhanced with a PI controller. The bidirectional buck-boost DC-DC converters (BBDC) are utilized to preserve a DC-link voltage stable. This is also storing additional hybrid energy in a large battery and is distributed to the system load; then there is a shortage of hybrid power. The load current power is regulated in terms of the frequency and enables it to be achieved using three vector control technique voltage source inverters (VSI). The results were offered to demonstrate a hybrid performance of this organization.

\section{Introduction}

Hybrid renewable power generation is becoming increasingly versatile and appealing to meet load in both standalone and grid-connected modes. The predictable power generation resources were finite and will be consumed in the next years [1]. In the current context of increased power genera- tion needs, leading to the advancements of sophisticated digital technology and a much more pleasant lifestyle, it is critical to produce more energy to close a significant gap between generation and transmission requirements. When the system has a power shortage, embedded production in distribution systems compensates for it. Fossil fuels presently account for the majority of the world's energy sources. 


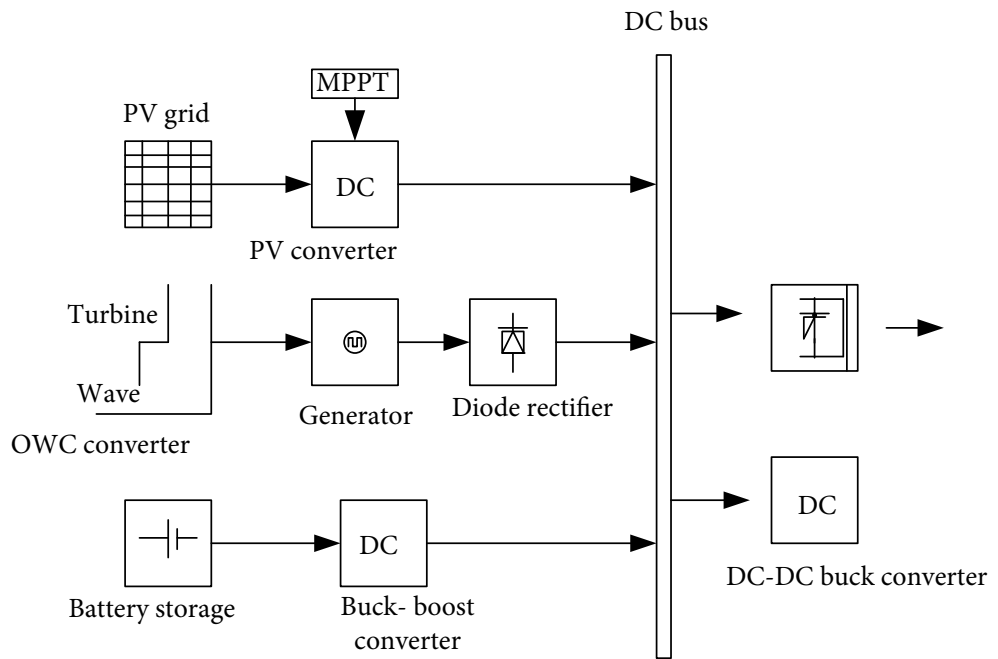

Figure 1: PV-wave proposed hybrid system block diagram.

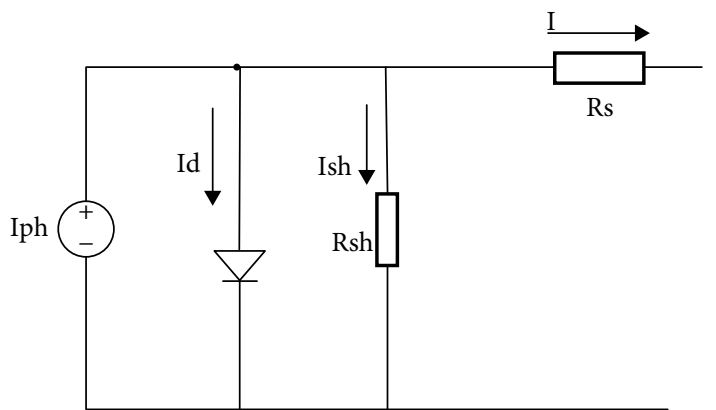

Figure 2: PV single-diode model.

TABLe 1: PV panel description.

\begin{tabular}{lc}
\hline Description & Parameter \\
\hline$I_{s c}$ & $5.97 \mathrm{~A}$ \\
$I_{M P}$ & $5.59 \mathrm{~A}$ \\
$V_{O C}$ & $64.3 \mathrm{~V}$ \\
$V_{M P}$ & $54.8 \mathrm{~V}$ \\
$N_{S}$ & 97 \\
$T$ & 25 \\
$P_{\max }$ & $305 \mathrm{~W}$ \\
$K_{I}$ & $3.6 \frac{\mathrm{mA}}{{ }^{\circ} \mathrm{C}}$ \\
$K_{V}$ & $-176.7 \frac{\mathrm{mV}}{{ }^{\circ} \mathrm{C}}$ \\
$N_{S e r}$ & 05 \\
$N_{p a r}$ & 67 \\
\hline
\end{tabular}

One of the benefits of fossil fuels is the ability to generate hydroelectric power from a single source. However, as fossil fuels are not renewable and therefore will eventually run out, they pose a threat to energy stability [2]. Even while the costs of energy generated from fossil fuels are inexpensive in com-

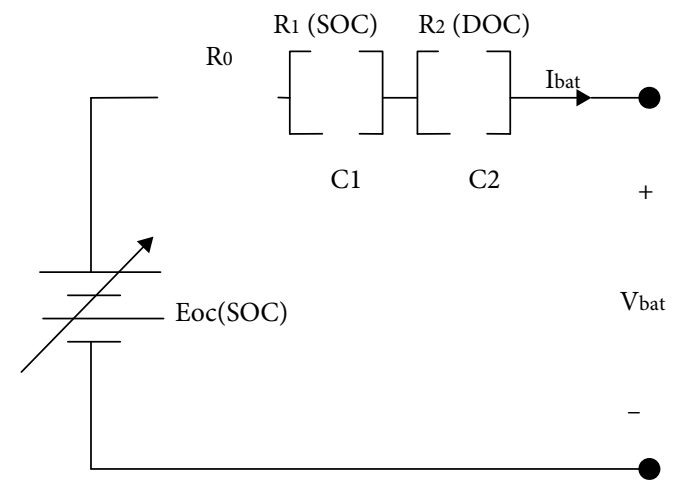

FIGURE 3: Model of battery.

parison to other possibilities, the transformation of such materials into electricity causes substantial pollution issues, such as the release of greenhouse gases into the atmosphere, which contributes to present global warming.

For decades, hybrid systems combining wind and PV energy sources have consumed a lot of attention. A hybrid organization may additionally incorporate a DC or AC converter, a packing area, filters, and a load management process control in addition to the energy sources [3]. All of these elements can be linked in a variety of ways. In renewable energy source applications, data-acquisition systems are commonly utilized to gather data on the deployed system's routine and estimation purposes. The information is initially conditioned with precise electronic circuits before being interfaced with a computer via a data achievement card. Solar energy is the most ecofriendly and speediest green energy source among some of the renewable energy sources [4]. However, the PV system's biggest disadvantage is that even the power it generates is greatly dependent on climatic circumstances. A PV system, for example, may not be able to generate any electricity at night or even during overcast times. As a result, the PV system generates power periodically, which implies that it may not be able to fully supply 


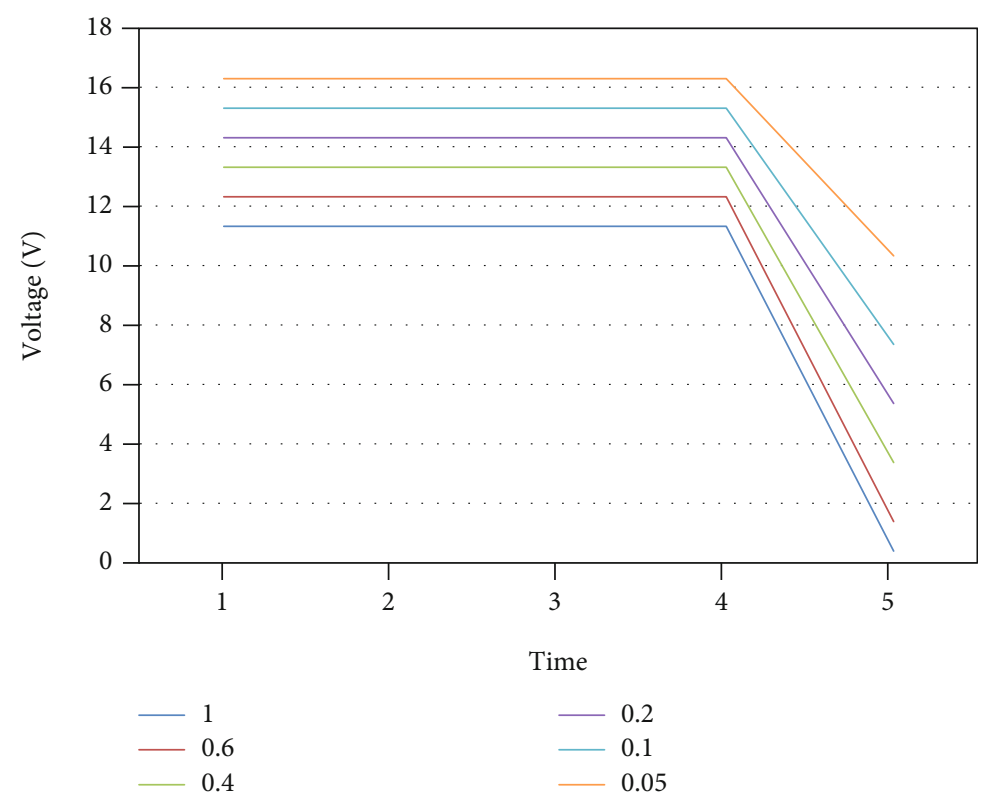

FIGURE 4: Characteristics of battery discharge.

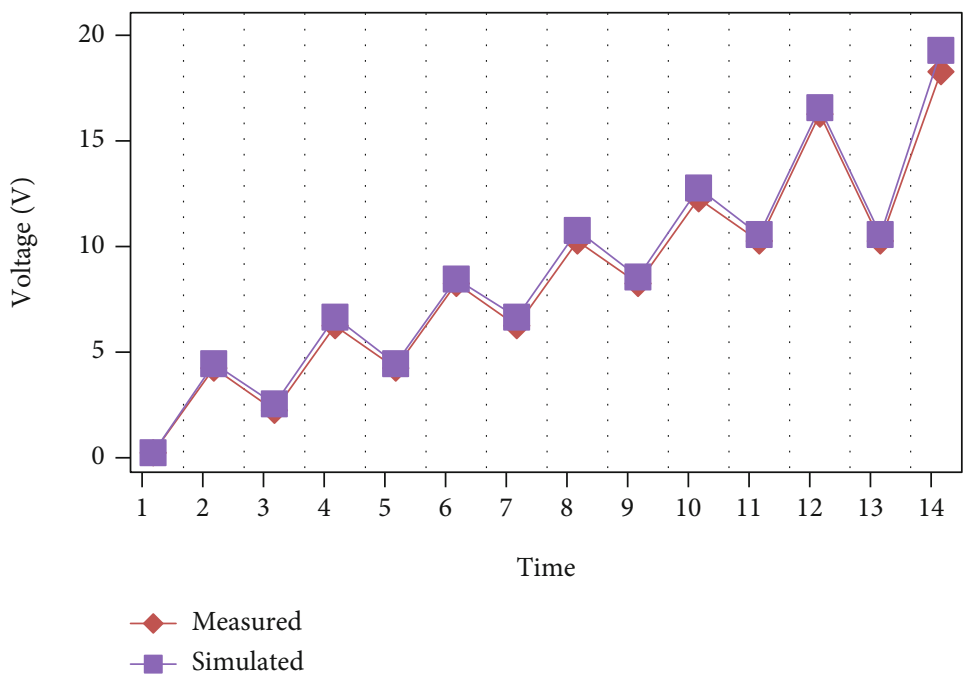

FIgURE 5: Yuasa NP18-12 battery, 0.2 pulse charge.

the power at any one time [5]. In an appropriate hybrid framework, this challenge is fixed by a PV integrating systems by some other energy storage technologies.

The ability to combine renewable sources of energy to form a hybrid system, on either side, is an ideal alternative for distributed energy-producing systems. As a result, alternative energy sources may be extra to the energy system to assure a long-term supply of electricity to the demand whenever the wind is inadequate. Solar energy, in addition to wind, is a frequently used renewable energy source [6]. It is also a reliant energy source, comparable to wind because the amount of energy created is based on numerous seasonal factors like irradiation angle, panel temperatures, and irradiance levels. As a result, the extra energy can be stored and used to charge equipment. The research can be carried out after simulating three distinct solar farms with such a rated output of $15 \mathrm{~kW}$ that are believed to be located in remote locations. The DC-DC converter system uses buck conversions with the perturb and observe (P\&O) MPPT control algorithm, which ensures that the power produced for each solar plant is stable [1]. Between the storage battery as well as the DClink, a BBDC is used to construct controller parameters, and a switching power inverter is used at the load-side end. To reduce the undesirable high-frequency vibrations caused by a load current of VSI depending on an inverter operating frequency, a humble passive L-C filter is put after the inverter at the load-side end [7]. The numerical solution can be used not only to evaluate the performance of the battery storage generated in PV-wave hybrid 


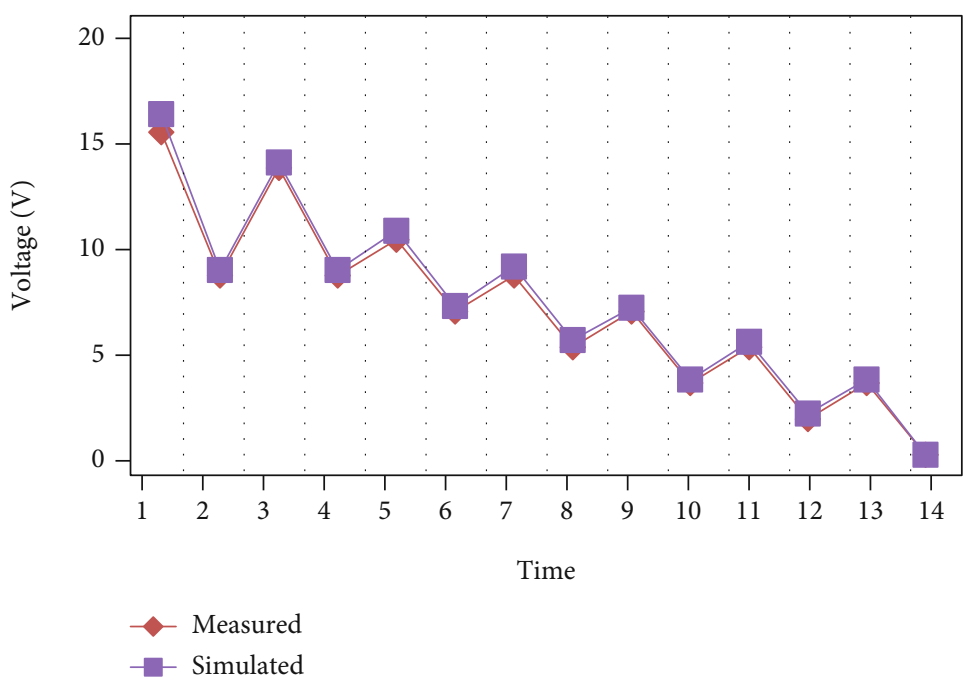

Figure 6: Yuasa NP18-12 battery, 0.2 pulse discharge.

TABLE 2: Modified P\&O algorithm's different control operations.

\begin{tabular}{|c|c|c|c|c|c|c|}
\hline Case & $(\Delta V)$ & $(\Delta P)$ & $(\Delta I)$ & TD & $G$ & $d$ \\
\hline 1 & Positive & Positive & Positive & Correct & High & $d=d+\Delta d$ \\
\hline 2 & Positive & Positive & Negative & Correct & Constant & $d=d-\Delta d$ \\
\hline 3 & Positive & Negative & Positive & Incorrect & High & $d=d-2 \Delta d$ \\
\hline 4 & Positive & Negative & Negative & Incorrect & Constant & $d=d+2 \Delta d$ \\
\hline 5 & Negative & Positive & Positive & Correct & Constant & $d=d+\Delta d$ \\
\hline 6 & Negative & Positive & Negative & Correct & Low & $d=d-\Delta d$ \\
\hline 7 & Negative & Negative & Positive & Incorrect & Constant & $d=d-2 \Delta d$ \\
\hline 8 & Negative & Negative & Negative & Incorrect & Low & $d=d-2 \Delta d$ \\
\hline
\end{tabular}

systems, but also to generate the amount of network hybrid renewable power output that meets the consumer load requirements in any situation. In this research, the proposed standalone PV-wave hybrid system model design was modeled and developed. The results are provided to demonstrate that the proposed system is effective.

\section{Related Works}

Grid extension to remote areas is fraught with technical and financial challenges. It has promoted the exploration and usage of renewable energy sources (RES) for decentralized power generation. The usage of renewable energy sources necessitates the use of a power source that is not always available. This difficulty has been mitigated to some extent by the installation of an energy storage unit (ESU) integration. The procedural review of a hybrid wind and PV production in a standalone method is presented in this study. The entire generation is influenced by associated components such as converters, storage units, controllers, and optimization strategies. Wind and solar energy are widely available, ubiquitous, and likely to show a significant role in a future energy market. To solve the problem of global warming caused by emissions from fossil-fuel-based thermal power stations, the analysis of the advancement of standalone renewable power units based upon PV and wind microgrids is included in this article [8].

A multi-input converter (MIC) is suggested, constructed, evaluated, simulated, and implemented to develop wind-PV power. The MIC is capable of processing both solar and wind energy, with its construction developed from the forward DC/DC conversion to a step-down/up power for a charger device, DC circulation uses. The MIC consists of a DSPbased control system, a higher adapted double-ended forward, a mutual output inductance, a lower altered doubleended forward, and an above altered double-ended forward. The two redesigned double-ended converters can work independently or in tandem to handle the hybrid renewable energy's variance under diverse air conditions. Improved results and lower volume can be obtained when the MIC is integrating the operation. The suggested MIC can recycle the energy held in the leaking inductance while achieving a high step-up voltage output. To attain a MPPT, the perturb and observe technique is used to pull a maximum output from wind turbines and solar panels. The MIC is built, examined, simulated, and put to the test. The possibility and 


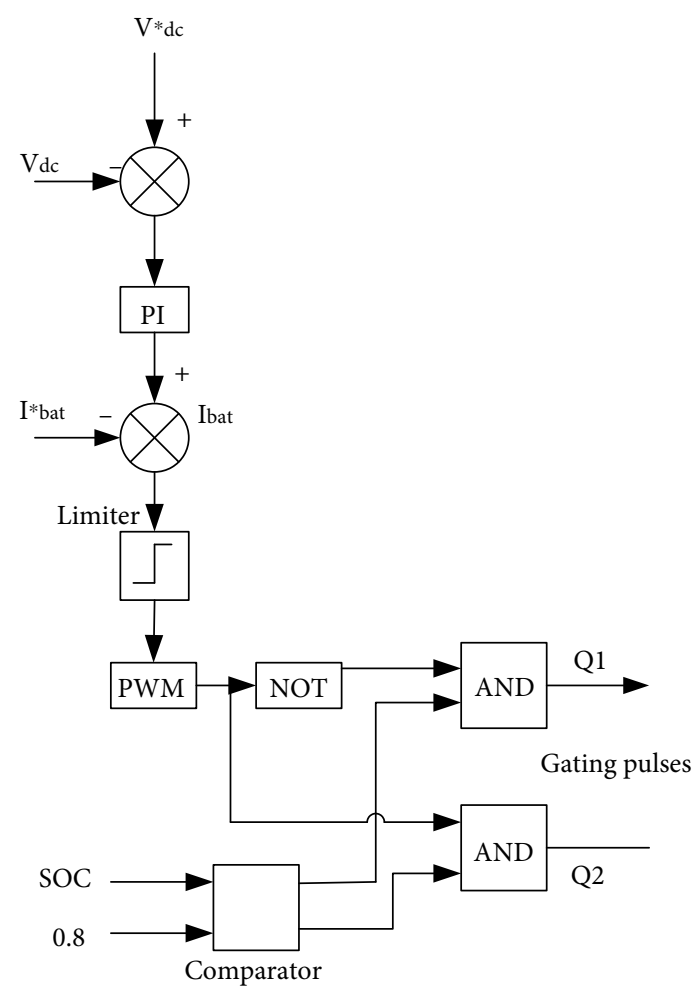

Figure 7: The DC-DC converter controller's diagram.

efficiency of a proposed multiconverter are shown through simulations or hardware tests [9].

An effective DC bus voltage parameter technique for a grid-connected photovoltaic (PV) system with a batteryenergy storage (BES) is evaluated in this research. A DC/ DC buck-boost converter connects a BES to the PV system's DC bus. During extreme disturbance circumstances, the converter enables the power of BES charge or discharge to adjust for a voltage of DC bus variance. In this method, the PV/BES system's DC bus voltage control can be improved over the traditional regulation, which is purely reliant on the voltage-sourced converter (VSC). The two control approaches, namely voltage-mode and currentmode controls, are used on the grid side VSC (G-VSC). For G-VSC voltage- and current-mode controls, as well as the BES DC/DC buck-boost converter regulators, the basic optimization method is used to optimize control parameters. For comparison, a new set of performance characteristics is generated for each of the power converters. The implementation of the developed improved control technique in comparison to existing methods is evaluated using PSCAD/ EMTDC-based simulated research studies [10].

The goal is to prevent load shedding and a difficult blackout while still providing a cheap and reliable electricity supply for both big and minor consumers. The additional advantage is that renewable energy supplies can be more efficiently and cost-effectively integrated into the existing national grid. Solar PV use has increased in recent years due to an increase in demand for renewable energy. Because of the solar PV production in a DC and maximum household appliances can run on DC, this article proposes an
AC-DC hybrid distribution network with a power management. EMS aids in the shifting of control of auxiliary loads, as well as forcing people to operate specified loads at specific times. These methods also aid in the management of overload during peak and off-peak hours. This explains how to build a DC-AC network using PV-solar and battery banks that integrate with a current organization. The outcome suggests that employing a hybrid AC-DC framework improves effectiveness and stability significantly. All of this working together improves overall efficiency, resulting in a power grid that is safe, cost-effective, dependable, and smart [11].

The supply of electricity could have a significant positive effect on reducing feelings of alienation and insecurity that orphanages often experience. The mathematical optimization analysis of a standalone photovoltaic electricity scheme that provided the required power requirements of an orphanage was given in this work. The National Aeronautics and Space Administration (NASA) surface meteorological and particularly a solar website provided solar sources for the software architecture at a location of $6^{\circ} 51^{\prime} \mathrm{N}$ latitude and $7^{\circ} 35^{\prime} \mathrm{E}$ longitude, with a yearly average of solar radiation of $4.92 \mathrm{kWh} / \mathrm{m}^{2} / \mathrm{d}$. This research is centred on the modeling, simulations, and improvement of the orphanage's power system. The orphanage's consumption of load habits is investigated and appropriately modeled for improvement. The suggested standalone solar power system analysis was performed and designed using the Hybrid Optimization Model for Electric Renewables (HOMER) software. The design was created to give the best configuration settings depending on hour-by-hour energy requirements and market data. This report included a full design, specification, and anticipated effectiveness of the software [12].

\section{Materials and Methods}

This study briefly explains the basic schematic plan of a hybrid PV-wave renewable power technology. Figure 1 depicts an entire block figure of a standalone PV-wave HRES. The proposed system involves of a PV system, a pulse width modulation (PWM), an OWC scheme, a BBDC with even a proportional-integral-derivative (PI) ratio of control duty, a storage battery, and insulated-gate bipolar transistor (IGBT) VSI located on the demand side [13]. A solar PV system consists of a PV grid as well as a DC-DC transmitter with the MPPT technique. In a photovoltaic panel, MPPT is utilized to raise system performance by controlling the DC-DC converter. The Darrieus turbine-driven permanent-magnet oscillator is bidirectional [14], and an AC-DC three-phase converter was used to build the OWC technology.

To satisfy the load need, the HRES uses a renewable photovoltaic and a wave-energy system as a major power generating source, with a battery bank serving as a backup energy storage device. As a result, if the HRES-generated power is insufficient to change the system load requirements, the battery storage will provide energy to equalize the system power requirement. The DC-link voltage has to be constant to connect a PV-wave, and the battery bank in hybrid architecture 
TABLE 3: OWC parameter.

\begin{tabular}{lccc}
\hline Length of chamber OWC & & $1.6 \mathrm{~m}$ & \\
Area of water surface inside a chamber & & $1.5 \mathrm{~m}^{2}$ & $0.013 \mathrm{~m}^{2}$ \\
Area of inlet turbine & Height of wave (m) & Period of wave (s) & Depth (m) \\
& 0.97 & 4.8 & 16.48 \\
Depth of water & 0.97 & 4.78 & 15.76 \\
& 0.87 & 4.76 & 15.74 \\
\hline
\end{tabular}

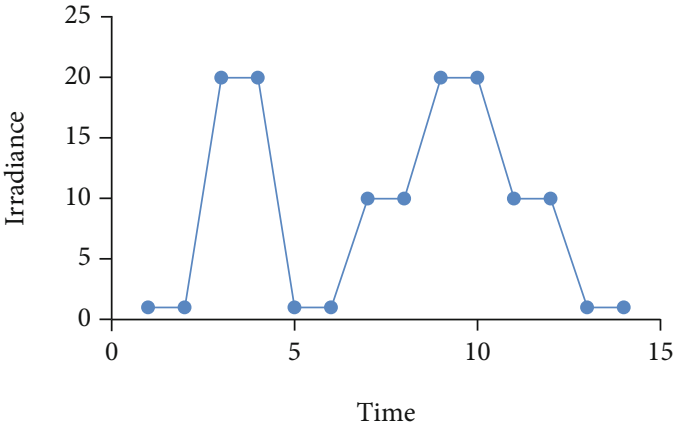

(a)

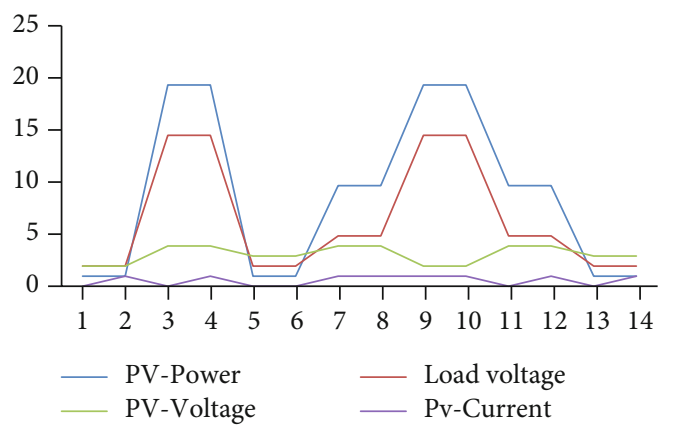

(b)

Figure 8: (a) An illumination profile of MPPT. (b) Matching results.

[15]. To retain a voltage DC-link constantly, the HRES uses a BBDC with a PI controller. To manage the voltage demand side in terms of an occurrence and breadth, a three-phase VSI with a very composite vector control method is employed at the demand side. The next sections provide a detailed summary of each aspect of organizational HRES and controllers.

3.1. PV Module Modeling. A PV-cell is made up of a $\mathrm{p}-\mathrm{n}$ junctional semiconducting material; then its equivalent circuit is revealed in Figure 2. This paper [16] refers to the mathematical analysis of PV systems. When solar energy falls upon that PV panel's surface, the PV process utilizes MPPT to get the most electricity. The formulas from the study referenced $[17,18]$ were used to create the PV system. Table 1 shows the PV array characteristics. The power of the solar SRP-305-WHT panel is simulated in a suggested hybrid renewable power generation using Matlab-2019 SIMULINK. I-V parameters of a photovoltaic panel are not linear. The experimental solution for the current would be as follows.

$$
I=I_{P V}-I_{o}\left[\exp \left(\frac{V+R_{s} I}{V_{t} x}\right)-1\right]-\frac{V+I R_{s}}{R_{p}}
$$

where $V_{t}=\mathrm{KTN}_{s} / q$.
As a result of the incident light, the current created is as follows:

$$
I_{P V}=\left(I_{P V n}+K_{I} \Delta_{T}\right) \frac{G}{G_{m}},
$$

where $\Delta_{T}=T-T_{n}$ and $I_{P V n}=\left(R_{p}+R_{s}\right) / R_{p} I_{s c_{n}}$.

The diode leakage current is stated as

$$
I_{o}=\frac{I_{s c_{n}}+K_{I} \Delta_{T}}{\exp \left(\left(V_{o c}+K_{I} \Delta_{T}\right) / n V_{t}\right)-1}
$$

A perfect photovoltaic cell's current is given as

$$
\begin{aligned}
I= & I_{P V} N_{P a r}-I_{0} N_{P a r}\left[\exp \left(\frac{V+R_{s}\left(N_{s e r} / N_{p a r}\right) I}{V_{t} x N_{s e r}}\right)-1\right] \\
& -\frac{V+R_{s}\left(N_{s e r} / N_{p a r}\right) I}{R_{p}\left(N_{s e r} / N_{p a r}\right)} .
\end{aligned}
$$

3.2. Oscillating Wave Column (OWC). This segment contains measured formulae that demonstrate the energy produced by the OWC scheme. The power produced at a wave turbine is made up of two terms: $P_{r}$ (pressure of air) and $P_{V}$ (velocity of air) [19]. As a result, the total energy of the chambers will be expressed to use the calculation 


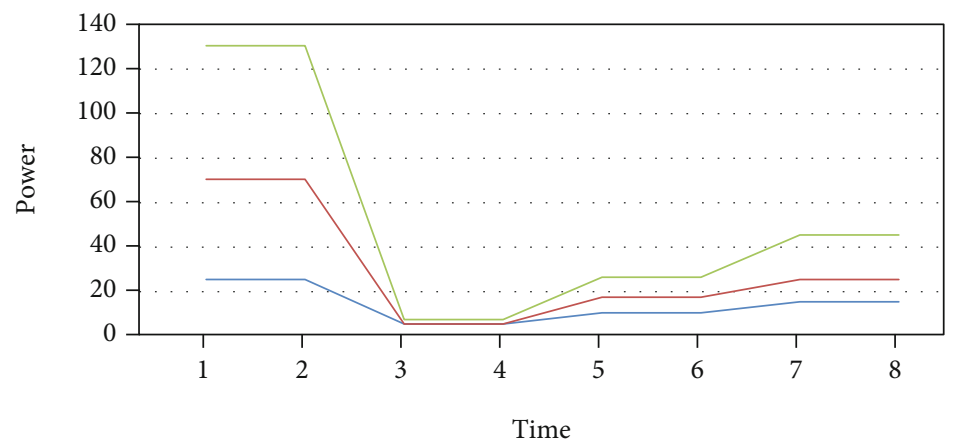

- Total chamber power

_ Chamber pressure power

Figure 9: Ocean wave chamber.

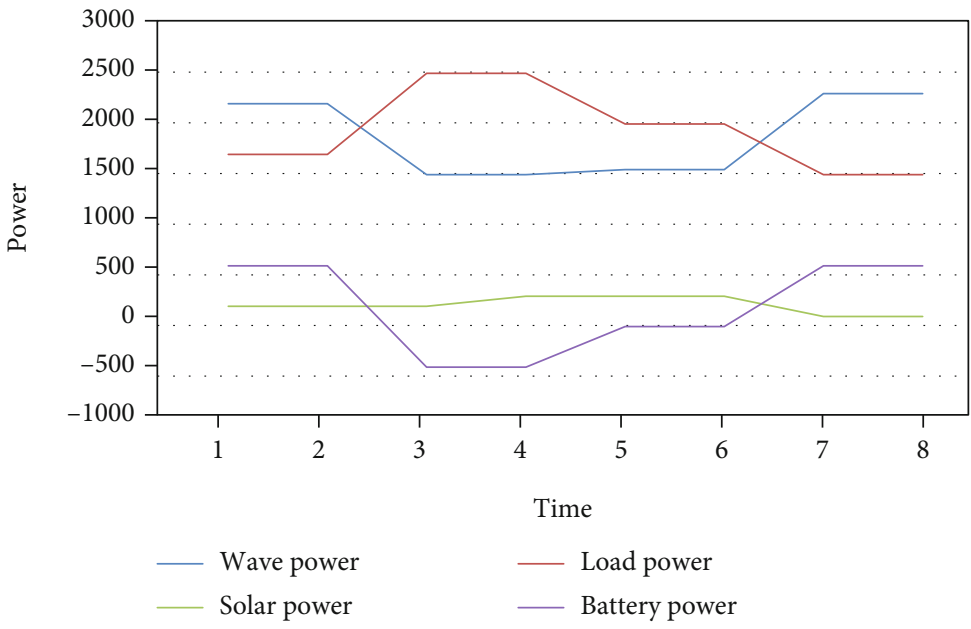

FIgURe 10: Distributed power by a hybrid PV-wave system.

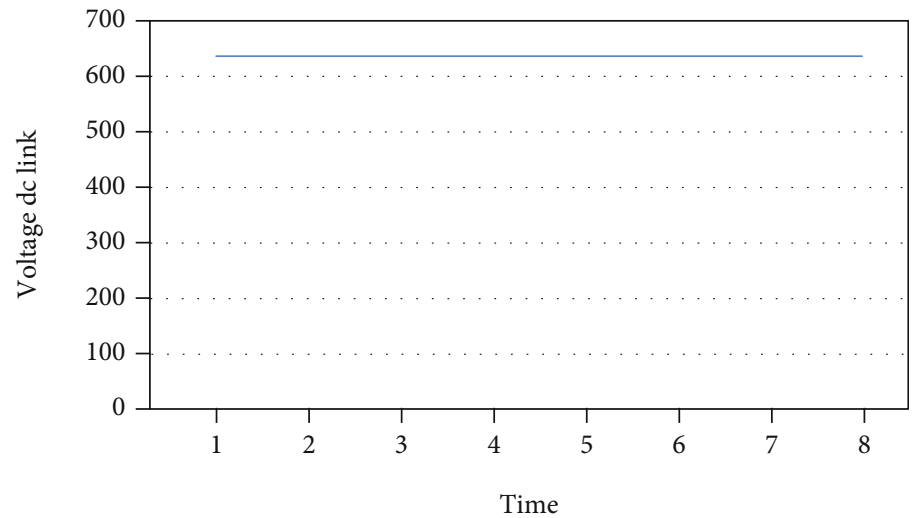

Figure 11: Voltage of DC-link.

below.

ating on the turbine is

Power of Chamber: $P_{c}=P_{V}+P_{r}$,

where due to atmospheric velocity term, the power $P_{V}$ oper-

$$
P_{V}=\rho A_{2} \frac{\left(V_{2}\right)^{3}}{2} .
$$




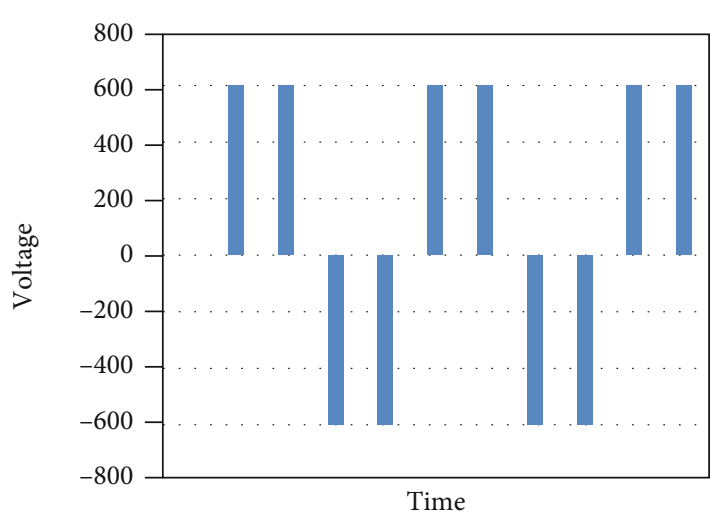

FIgURE 12: Output voltage of inverter.

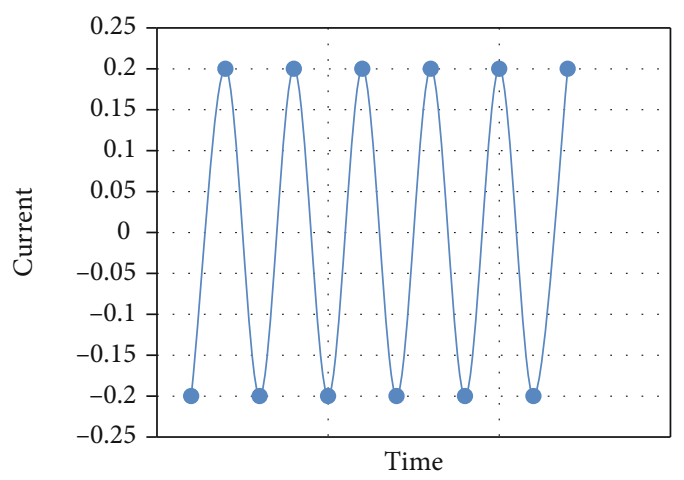

FIGURE 13: Three-phase current.

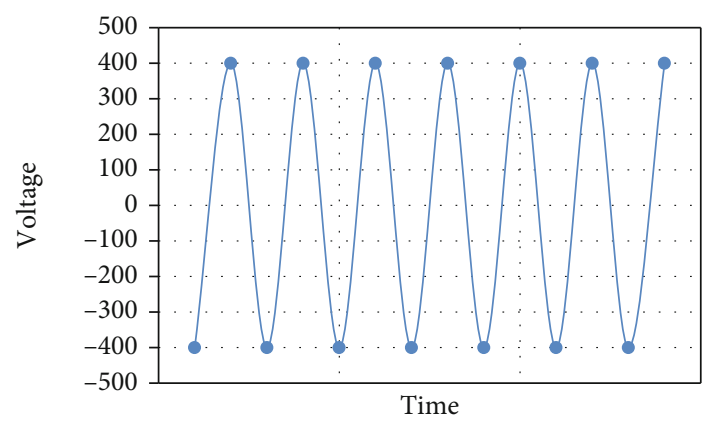

FIGURE 14: Three-phase voltage.

attainable to the turbine is

$P_{r}=\left[-\frac{X_{1}}{X_{2}} \frac{W_{\text {in }}^{2}}{\theta^{2}} \omega^{2}\left\{2 \cos (\omega t)^{2}-1\right\} \times \operatorname{Sin}^{2}\left(\frac{\theta}{2}\right)+\frac{Q_{X}}{A_{2}}\left(V_{2}-V_{1}\right)\right] \times Q_{x} \times \rho$.

Because the OWC's independent power is the product of a generator coefficient power $C_{O}$, the overall power output is produced by an OWC that equals

$$
P_{\text {total }}=\left(P_{v}+P_{r}\right) \times C_{O}
$$

3.3. Battery Storage System. In PV systems, batteries are also the primary storage technique. The model of battery is uti- lized to investigate the impacts of a different rate of charge, as well as the battery's state of charge (SOC) and state of health (SOH) [20]. Various test scenarios can be used to determine the best battery size for a specific application. Without any need for costly staging areas, simulations are utilized to compare alternative storage methods.

Figure 3 depicts a simple transmission line battery concept. The model of battery considers the battery's state of charge (SOC) and depth of charge (DOC). With a rising current discharge, the battery's serviceable capacity decreases; the DOC of the battery monitors the segment of the battery's capacity to a functioning capacity [21]. An open-circuit battery voltage $E_{o c}$, internal resistance $R_{0}$, and two RC-parallel branching are included in the model. The formulas for the system are displayed on the following equations.

$$
\begin{gathered}
E_{o c}=E_{0}-K_{e}(1-S O C), \\
R_{1}=R_{10} e\left(-K_{1}(1-S O C)\right), \\
R_{2}=\frac{R_{20}}{D O C}, \\
S O C=1-\frac{1}{C_{n}} \int i_{\text {batt }} d \tau, \\
D O C=1-\frac{1}{C\left(i_{\text {avg }}\right)} \int i_{\text {batt }} d \tau,
\end{gathered}
$$

where SOC is the battery's condition of state charge, DOC is the battery's condition of deep charge, $C_{n}$ is the capacity of a battery, $C\left(i_{\text {avg }}\right)$ is the current-dependent capacity of a battery, $E_{0}$, when the batteries are fully charged, is the opencircuit voltage, $K_{e}$ is a constant, $K_{1}$ is constant, $\mathrm{R}_{10}$ is a $1^{\text {st }}$ constant RC branch in $\Omega, \mathrm{R}_{20}$ is a $2^{\text {nd }}$ constant RC branch in $\Omega, \tau_{1}$ is the $1^{\text {st }}$ the time constant RC branch in $\Omega$, and $\tau_{2}$ is the $2^{\text {nd }}$ the time constant RC branch in $\Omega$.

For various C-rates, Figure 4 displays the modeled characteristics of discharge curves for the Yuasa Np18-12 leadacid batteries. $E_{0}=12.84, K_{e}=1.7, R_{0}=0.12 \Omega$ for charge and 0.057 for discharge, $R_{10}=0.16 \Omega$ for charge and 0.02 for discharge, $K_{1}=7$, and $R_{20}=0.0055 \Omega$ in both charging and discharging, according to testing on the Yuasa Np1812 battery. The battery's $0.2 \mathrm{C}$ pulse charging and discharging is shown in Figures 5 and 6, correspondingly.

A solar panel, conversion, loads, and battery bank are the most frequent components of freestanding photovoltaic systems. When there are differences between accessible and necessary energy, the energy formed by a photovoltaic module is retained in a rechargeable battery to satisfy the requirements of demand [22]. Charge-discharge devices have wider sheets than vehicle batteries and are designed to be continually drained to that more at $80 \%$ depth of discharge (DOD), providing them a good alternative for PV storage. The unit is normally designed to power a capacity for 2-3 days, resulting in a great rechargeable battery which will have to be changed every several decades.

The energy transfer from a PV module to the battery and a demand is controlled by a battery management system (BMS). Measuring the battery SOC, adjusting the DC-DC 
converter pulse width, and applying the charging method are all tasks performed by the BMS. The BMS is based on an estimate of the SOC. The battery charge and discharge are affected by the current battery SOC [23]. The DC-DC inverter is utilized to convert MPPT tracking to charge the battery and power the demand. Sensors and measuring circuits measure the photovoltaic panel, battery, load voltage, and current, as well as the solar panel and battery condition [24]. The control algorithm uses these analytics to enhance the system's activity to make the effective use of existing energy to keep a battery at such a maximum SOC while also guaranteeing the demand requirements are fulfilled throughout all times.

3.4. Modified P\&O MPPT. The standard $\mathrm{P} \& \mathrm{O}$ is not ideal for tracking changeable radiation levels since it also oscillates frequently about the MPP whenever the PV system's peak power is generated at a specific operational point and deviates from MPP if solar irradiation changes [25]. The divergence is caused by a shift in the level of irradiation. As a result, both of the aforementioned factors result in energy losses in the PV module, as well as limitations in typical $\mathrm{P} \& \mathrm{O}$ solutions. To circumvent these limitations, a modified $\mathrm{P} \& \mathrm{O}$ approach is assigned. By changing the current $(I)$ variable in the algorithm, the improved $\mathrm{P} \& \mathrm{O}$ improves the network efficiency.

The proposed MPPT algorithm behaves like classic P\&O under constant irradiance. When the irradiance changes, the MPPT algorithm behaves differently than the conventional $\mathrm{P} \& \mathrm{O}$ algorithm. The number of iterations is increased for velocity tracking during poor tracking periods [26]. This MPPT algorithm can distinguish between power fluctuations caused by solar illumination and measured voltage disruptions. As a result, according to the cited article, MPP deviation can be ignored. Table 2 details the different control measures of the improved $\mathrm{P} \& \mathrm{O}$ algorithm, and it may cover up to eight different scenarios. The tracking motion and controlling success are determined by the power differential $(P)$. There are two types of cases that can be explored.

Case 1. The PV panel is in continuous irradiation if the changes in voltage $(\Delta V)$ and current $(\Delta I)$ have opposite signs.

Case 2. If the $(\Delta V)$ and $(\Delta I)$ take almost the same sign, the $\mathrm{PV}$ array gets irradiated differently.

3.5. DC-Link Voltage Control. A planned PV-wave hybrid standalone system's circuit layout is presented in this section. A neutral device is connected among the capacitors attached even before VSI enabling supplying single-phase and three-phase applications to the present scheme. The DC-link portion of a BBDC is linked to the battery bank in this research; the major goal of the BBDC's management is to keep a continual voltage DC-link as a standard value, as well as discharge or charge power from or to the batteries reserve according to with an essential load power [27]. Figure 7 shows a schematic representation of the battery system BBDC controller. By employing BBDC, the value of a large battery can indeed be considered lower than the standard DC-link voltage $\left(V_{d c}^{*}\right)$, resulting in fewer batteries needing to be synchronized. The battery capacity voltage is maintained around $300 \mathrm{~V}$ in the planned standalone systems, while $V_{d c}^{*}=650 \mathrm{~V}$.

The battery's bank of depletion is assumed to be $60 \%$ in this work, and it is created on the idea it should deliver an electric power of up to $2.5 \mathrm{~kW}$, and demand is around an hour whenever the produced energy wave is zero.

The value of the inductance in a BBDC is critical for it to operate in the charging process. In addition, the presence of an inductor on the battery bank side leads to decreased ripple current, resulting in a longer lifetime and improved efficiency [28]. The operation of the charging process is also influenced by the incoming and outgoing currents, the value of the capacitors, and the switching speed. The inductance and capacitor values are as follows:

$$
\begin{gathered}
\text { Inductance } L_{2}=\frac{V_{\text {Battery }} \times\left(V_{\text {DClink }}-V_{\text {Battery }}\right)}{I_{\text {Battery }} \times V_{\text {DClink }} \times f_{w}}, \\
\text { Buck mode capacitance } C_{2}=\frac{I_{\text {Battery }} \times K_{L}}{f_{w} \times 8 \times V_{\text {Battery (ripple })}}, \\
\text { Boost mode capacitance } C_{3}=\frac{I_{\text {DClink }} \times D_{\text {Boost }}}{V_{\text {DClink }(\text { ripple })} \times f_{w}},
\end{gathered}
$$

where $V_{\text {Battery }}$ is the energy of battery voltage, $V_{\text {DClink }}$ is the voltage DC-link, $I_{\text {DClink }}$ is the current DC-link, $I_{\text {Battery }}$ is the current of battery storage, $V_{\text {Battery(ripple) }}$ is the output of buck side preferred a ripple voltage, $V_{\text {DClink(ripple) }}$ is the boost-side output preferred a ripple voltage, $K_{L}$ is the approximate coefficient of measurement current ripple at the backside, and $f_{w}$ is a scaling factor.

3.6. VSI Monitoring on the Load Side. A three-phase control technique VSI has utilized an interface device among a user load as well as the DC link voltage at a load end. The speed and amplitude only at the user load end are controlled by the load-side VSI controller. Since there is no electricity generation that developed a sense in the suggested HRES technology, its maximum output voltages should be managed in terms of primary frequency magnitude [29]. The output voltage is regulated using the state space modulation technique as the necessary hybrid or loading power varies.

The vector control method is adopted in this study, which depends on the simultaneously rotating scheme presented. Using the selected maximum output voltages electrical frequencies, the three-phase $V_{x}, V_{y}$, and $V_{z}$ voltages and $I_{x}, I_{Y}$, and $I_{z}$ currents should be translated and monitored from a standard stationary frame $a-b-c$ to a comparison by a rotating frame of $d-q .220 \mathrm{~V}$ and $50 \mathrm{HZ}$ are the defined root mean square (RMS) values for the output voltage waveform and load voltage rate in this research. 
The following are the voltage formulas by using references rotating $d-q$ frame transition:

$$
\begin{aligned}
& V_{d}=V_{d i}-H_{f} \frac{d i_{d}}{d t}+H_{f} \omega i_{q}, \\
& V_{q}=V_{q i}-H_{f} \frac{d i_{q}}{d t}-H_{f} \omega i_{d} .
\end{aligned}
$$

The active and reactive power is calculated using the $d$ $-q$ reference rotational frame conversion.

$$
\begin{gathered}
\text { Active power } P=\frac{3}{2}\left(i_{d} v_{d}+i_{q} v_{q}\right), \\
\text { Reactive power } \mathrm{Q}=\frac{3}{2}\left(i_{q} v_{d}+i_{d} v_{q}\right) .
\end{gathered}
$$

If the standard rotational frame is $v_{q}=0$ and $v_{d}=|V|$, the power of active and reactive formulas is as follows:

$$
\begin{aligned}
& P=\frac{3}{2} i_{d} v_{d}=\frac{3}{2}|V| i_{d}, \\
& Q=\frac{3}{2} i_{q} v_{d}=\frac{3}{2}|V| i_{q} .
\end{aligned}
$$

As a result, regulating direct and quadrature current components can regulate real and reactive power, correspondingly. Case $V_{d}^{*}$ could also be controlled by it for resistors.

$$
V_{d}^{*}=\sqrt{2} V_{R M S}^{*}
$$

The output RMS phase reference voltage value is $V_{R M S}^{*}$. PI controllers manage the capacity voltage output in internal control loops and a charge output waveform in external monitoring loops in this control technology [30]. The Ziegler Nichols tuning approach is utilized to adjust all of the PI controllers in this article.

\section{Result and Discussion}

In the OWC system, battery storage, PV system, and BBDC with a PI control duty cycle, a voltage regulator is positioned at a lateral loading that makes up the proposed hybrid model. PV array and DC-DC converters with an MPPT algorithm make up a PV-solar system. The bidirectional turbine was powered by an asynchronous generator (SG) and an AC-DC three-phase rectification in OWC systems. The $\mathrm{PV}$-renewable and wave-energy systems are employed as the major power generating source to satisfy systems demand requirement in hybrid renewable energy source (HRES), while stored energy is being used as a standby energy storage system. The DC-link voltage should be constant to interface PV-wave and a battery system in hybrid architecture. To keep a DC-link voltage steady, the HRES uses a BBDC with a PI controller.

The simulations were divided into four sections. The model of an ocean wave power converter was completed first, followed either by simulation of a photovoltaic system.
The model is then run using a combination of ocean wave and PV systems, as well as a battery-energy storage system. Finally, the whole modeling of a hybrid power system, which would be founded on grid connectivity, has been completed. The simulation parameters are listed in Tables 3.

A strict profile for fluctuating solar radiation is utilized to demonstrate the usefulness of the suggested method. As suggested by the efficiency test, EN 50530, this profile includes several geometries such as step-up, step-down, ramp-up, and ramp-down. Two different slopes are chosen, with values of $1875 \mathrm{~W} / \mathrm{m}^{2} / \mathrm{s}$ and $2500 \mathrm{~W} / \mathrm{m}^{2} / \mathrm{s}$, respectively, as shown in Figure 8(a). The suggested tracker may be thoroughly tested under intermittent and stable situations using this profile. The time of a test was prolonged by 4 seconds, while the temperature remained constant at 25 degrees Celsius. For both the P\&O method and its version, the switching frequency step size is $\Delta d=0.0002$.

To begin, the suggested $\mathrm{P} \& \mathrm{O}$ sensor was tested under a certain irradiance profile, with the simulated results shown in Figure 8(b). PV grandeurs including voltage $(V)$, current $(I)$, load voltage $\left(V_{0}\right)$, and power $(P)$ have their waveforms shown. The various grandeurs have acquired the same levels as the photovoltaic curve, as may be observed. It may be proven that the conversion utilized is a voltage step by comparing the behaviors of $V$ and $V_{0}$. Moreover, the development of irradiance has a greater impact on the morphologies of $I$ and $P$ than on $V$, which will only be marginally influenced.

4.1. Ocean Wave Chamber Results. Figure 9 depicts the energy produced as a result of the airspeed and pressure of the chamber, respectively. The output total power is calculated using Equation (4), as shown in the figure. According to Figure 9, the chamber has a maximum power output of $8500 \mathrm{~W}$. Figure 9 depicts the entire power output of the ocean wave system.

Figures 10 and 11 demonstrate the output of a buckboost bidirectional DC-DC converter regulator. Figure 10 depicts the distribution of the power chart of produced solar power, load power, wave power, and battery-energy power. Figure 10 depicts how, when wave power, solar power, and necessary demand vary, the power first from the battery system varies (discharged/charged) to preserve a total power consistency. As shown in Figure 10, when the produced fusion power is greater than the needed load power, the regulator can charge a battery bank; when the necessary load power is greater than the produced hybrid power, the regulator can drain the battery bank. Furthermore, when the hybrid power and load demand fluctuate, it can preserve a continuous voltage DC-link at $650 \mathrm{~V}$, as demonstrated in Figure 11. Figure 10 shows that the lack of solar power after 12 seconds indicates a foggy or evening phase. In this situation, both wave-energy and battery-energy power match the load requirements in every direction. As a result, the efficiency of the buck-boost DCDC multilevel inverter controller both in rapid and steady-state hybrid energy and state of charge conditions is quite excellent.

Finally, the DC-link is linked to a three-phase VSI. Figures 12-14 illustrate the results achieved after attaching 
a hybrid approach to a three-phase grid. The load voltage depicted in Figure 14 is completely sinusoidal in a waveform.

\section{Conclusion}

Renewable energy resources are inconsistent, and designing a solar PV power producing system is difficult. An innovative freestanding PV-wave control scheme is conceived and modeled, complete with appropriate energy flow controllers. In this difficult situation, this study is aimed at constructing a hybrid power production system consisting of energy battery storage PV-wave renewables and an effective power control method to fulfill the load requirements. The results show that a controller can keep the voltage DC-link steady despite variations in produced hybrid power and necessary load power. Moreover, the controller is designed in such a way that battery storage can collect surplus energy produced by the combination organization and send it to the load demand throughout a hybrid network outage by managing the BBDC. The suggested hybrid system performs effectively in steady-state energy and also intermittent load power, solar, and wave circumstances. This study can be viewed as a first step in developing a standalone PV-wave hybrid model.

\section{Data Availability}

The data used to support the findings of this study are included within the article.

\section{Conflicts of Interest}

The authors declare that there is no conflict of interest regarding the publication of this article.

\section{Acknowledgments}

The authors would like to express their gratitude towards the Saveetha School of Engineering (SIMATS), Chennai, for providing the necessary infrastructure to carry out this work successfully.

\section{References}

[1] P. Rathod, S. K. Bhuyan, and S. K. Mishra, "Power management system using modified control strategy in hybrid renewable generation system connected to grid," International Journal of Renewable Energy Research, vol. 11, no. 3, pp. 1189-1204, 2021.

[2] T. M. Amirthalakshmi, S. Ramesh, R. T. Prabu et al., "A novel approach in hybrid energy storage system for maximizing solar PV energy penetration in microgrid," International Journal of Photoenergy, vol. 2022, Article ID 3559837, 2022.

[3] E. Kabalci, "Design and analysis of a hybrid renewable energy plant with solar and wind power," Energy Conversion and Management, vol. 72, pp. 51-59, 2013.

[4] G. Ramkumar, S. Sahoo, T. M. Amirthalakshmi et al., "A short-term solar photovoltaic power optimized prediction interval model based on FOS-ELM algorithm," International Journal of Photoenergy, vol. 2021, Article ID 3981456, 2021.
[5] N. H. Samrat, N. B. Ahmad, I. A. Choudhury, and Z. B. Taha, "Modeling, control, and simulation of battery storage photovoltaic-wave energy hybrid renewable power generation systems for island electrification in Malaysia," The Scientific World Journal, vol. 2014, 21 pages, 2014.

[6] L. Bernal-Agustín and R. Dufo-López, "Simulation and optimization of stand-alone hybrid renewable energy systems," Renewable and Sustainable Energy Reviews, vol. 13, no. 8, pp. 2111-2118, 2009.

[7] S. Das and A. K. Akella, "Power flow control of PV-windbattery hybrid renewable energy systems for stand-alone application," International Journal of Renewable Energy Research, vol. 8, no. 1, pp. 36-43, 2018.

[8] P. Kumar and D. K. Palwalia, "Decentralized autonomous hybrid renewable power generation," Journal of Renewable Energy, vol. 2015, 18 pages, 2015.

[9] C.-L. Shen and S.-H. Yang, "Multi-input converter with MPPT feature for wind-PV power generation system," International Journal of Photoenergy, vol. 2013, 13 pages, 2013.

[10] M. Z. Daud, A. Mohamed, and M. A. Hannan, “An optimal control strategy for DC bus voltage regulation in photovoltaic system with battery energy storage," The Scientific World Journal, vol. 2014, Article ID 271087, 2014.

[11] S. Rauf and N. Khan, "Application of DC-AC hybrid grid and solar photovoltaic generation with battery storage using smart grid," International Journal of Photoenergy, vol. 2017, Article ID 6736928, 2017.

[12] V. A. Ani, "Feasibility and optimal design of a stand-alone photovoltaic energy system for the orphanage," Journal of Renewable Energy, vol. 2014, Article ID 379729, 2014.

[13] A. Martinez, D. Abbes, and G. Champenois, "Eco-design optimisation of an autonomous hybrid wind-photovoltaic system with battery storage," IET Renewable Power Generation, vol. 6, no. 5, pp. 358-371, 2012.

[14] A. Jemaa, O. Zarrad, M. A. Hajjaji, and M. N. Mansouri, "Hardware Implementation of a fuzzy logic controller for a hybrid wind-solar system in an isolated site," International Journal of Photoenergy, vol. 2018, Article ID 5379864, 2018.

[15] G. N. L. P. Raj and V. Kirubakaran, "Energy efficiency enhancement and climate change mitigations of SMEs through gridinteractive solar photovoltaic system," International Journal of Photoenergy, vol. 2021, Article ID 6651717, 2021.

[16] A. Laudani, F. R. Fulginei, and A. Salvini, "Identification of the one-diode model for photovoltaic modules from datasheet values," Solar Energy, vol. 108, pp. 432-446, 2014.

[17] M. G. Villalva, J. R. Gazoli, and E. Ruppert Filho, "Modeling and circuit-based simulation of photovoltaic arrays," in 2009 Brazilian Power Electronics Conference, pp. 1244-1254, Bonito-Mato Grosso do Sul, Brazil, 2009.

[18] S. K. Bhuyan, P. K. Hota, and B. Panda, "Modeling and simulation of hybrid energy system supplying $3 \varnothing$ load and its power quality analysis," International Journal of Renewable Energy Research, vol. 8, no. 1, pp. 592-603, 2018.

[19] S. Ahmad, M. J. Uddin, I. H. Nisu, M. M. Ahsan, I. Rahman, and N. H. Samrat, "Modeling of Grid Connected Battery Storage Wave Energy and PV Hybrid Renewable Power Generation," in 2017 International Conference on Electrical, Computer and Communication Engineering (ECCE), pp. 375380, Cox’s Bazar, Bangladesh, 2017.

[20] M. Nayeripour, M. Hoseintabar, and T. Niknam, "Frequency deviation control by coordination control of FC and double- 
layer capacitor in an autonomous hybrid renewable energy power generation system," Renewable Energy, vol. 36, no. 6, pp. 1741-1746, 2011.

[21] J. Mudi, C. K. Shiva, B. Vedik, and V. Mukherjee, "Frequency stabilization of solar thermal-photovoltaic hybrid renewable power generation using energy storage devices," Iranian Journal of Science and Technology, Transactions of Electrical Engineering, vol. 45, no. 2, pp. 597-617, 2021.

[22] M. E. Glavin, P. K. W. Chan, S. Armstrong, and W. G. Hurley, "A stand-alone photovoltaic supercapacitor battery hybrid energy storage system," in 2008 13th International Power Electronics and Motion Control Conference, pp. 1688-1695, Poznan, Poland, 2008.

[23] S. Moghaddam, M. Bigdeli, M. Moradlou, and P. Siano, "Designing of stand-alone hybrid PV/wind/battery system using improved crow search algorithm considering reliability index," International Journal of Energy and Environmental Engineering, vol. 10, no. 4, pp. 429-449, 2019.

[24] F. L. Tofoli, D. de Castro Pereira, and W. J. de Paula, "Comparative study of maximum power point tracking techniques for photovoltaic systems," International Journal of Photoenergy, vol. 2015, Article ID 812582, 2015.

[25] M. A. Abdourraziq, M. Ouassaid, M. Maaroufi, and S. Abdourraziq, "Modified P\& O MPPT technique for photovoltaic systems," in 2013 International conference on renewable energy research and applications (ICRERA), pp. 728-733, Madrid, Spain, 2013.

[26] B. Bhandari, S. R. Poudel, K.-T. Lee, and S.-H. Ahn, "Mathematical modeling of hybrid renewable energy system: a review on small hydro-solar-wind power generation," International Journal of Precision Engineering and Manufacturing-green Technology, vol. 1, no. 2, pp. 157-173, 2014.

[27] M. Merai, M. W. Naouar, and I. Slama-Belkhodja, "An improved DC-link voltage control strategy for grid connected converters," IEEE Transactions on Power Electronics, vol. 33, no. 4, pp. 3575-3582, 2018.

[28] L. Shen, J. Chen, Z. Jin, Z. Liu, D. Zhou, and C. Wu, "Resonating power decoupling using multifunctional bidirectional DC/ DC converter in hybrid railway traction application," IEEE Transactions on Power Electronics, vol. 37, no. 1, pp. 404415, 2022.

[29] D. Jing, J. Shi, P. Meyrueis, and H. Zhou, "Semiconductorbased photocatalytic, photoelectrochemical, and photovoltaic solar-energy conversion," vol. 2014, Article ID 695204, 2014.

[30] E. K. Anto, J. A. Asumadu, and P. Y. Okyere, "PID control for improving P\&O-MPPT performance of a grid-connected solar PV system with Ziegler-Nichols tuning method," in 2016 IEEE 11th Conference on Industrial Electronics and Applications (ICIEA), pp. 1847-1852, Hefei, China, 2016. 